\title{
Fraction distribution and risk assessment of heavy metals in sediments of Moshui Lake
}

\author{
LIU Honglei, LI Liqing, YIN Chengqing*, SHAN Baoqing \\ State Key laboratory of Environmental Aquatic Chemistry, Research Center for Eco-Environmental Sciences, Chinese Academy of Sciences, \\ Beijing 100085, China. E-mail: Hongleiliu@126.com
}

Received 15 June 2007; revised 4 September 2007; accepted 11 September 2007

\begin{abstract}
To examine the status and risk of heavy metal pollution in urban lakes, in China, the distribution of several heavy metals (e.g., Cr, $\mathrm{Cu}, \mathrm{Ni}, \mathrm{Pb}, \mathrm{Zn}$ ) in the sediment of Moshui Lake, Hangyang District, Wuhan City, was characterized. The process of rapid urbanization and industrialization of the district was also studied to find out its relationship with the metal accumulation profile in the sediment. It was found that the total concentration of heavy metals in the sediment was higher than the severe effect level (SEL), at all sampling sites, except those in the riparian zone. The $\mathrm{Cr}$ and $\mathrm{Cu}$ maximum concentrations were 1,780 and 1,250 mg/kg, approximately 16 and 11 times as much as the SEL values, and they appeared as deep as $32 \mathrm{~cm}$ in one sample. The carbonate and exchangeable fractions of $\mathrm{Zn}$ were more than $50 \%$ of the total $\mathrm{Zn}$ content, resulting in very high risk according to the Risk Assessment Code (RAC). For Cu and $\mathrm{Ni}$, a medium RAC value was found for carbonate and exchangeable fractions of $11 \%-20 \%$. As sensitive indicators of contaminants in aquatic systems, heavy metals in the sediment reflect the outcome of regional urbanization, industrialization, and environmental management. With rapid urbanization, sedimentary $\mathrm{Pb}$ and $\mathrm{Zn}$ concentrations increased. The experimental results showed that high sedimentary heavy metal concentrations had resulted from rapid urbanization and industrialization, which would absolutely lead to substantial aquatic environmental decline in urban lakes.
\end{abstract}

Key words: distribution; heavy metal; risk; sediment; urbanization

\section{Introduction}

Heavy metal contamination of sediments can critically degrade aquatic systems (Charkhabi et al., 2005). Their release from the sediment can make them enter the aquatic ecosystems and bring about severe problems (Mohammed and Markert, 2006). Despite the differences in toxic effects of the metals with different metals as well as their concentrations and the time of exposure (Mohammed and Markert, 2006), their concentrations are reliable indicators of ecosystem health (Singh et al., 2005). In sediments, heavy metals can be present in a number of chemical forms, exhibiting different physical and chemical behaviors with respect to chemical interactions, mobility, biological availability, and potential toxicity (Arnason and Fletcher, 2003; Singh et al., 2005). It has been found that the speciation of a metal, rather than its total concentration, is the key to understand its effect on the biota (Allen and Hansen, 1996), as well as its biogeochemical transformation and ultimate fate (Billon et al., 2002).

Many studies have found that the land use of an urban area poses a significant impact on the heavy metal contamination in soils (Kim et al., 1998; McAlister et al., 2005; Han et al., 2006), and aquatic systems (Fan et

\footnotetext{
* Corresponding author. E-mail: cqyin@263.net.
}

al., 2002; Lee et al., 2003; Samecka-Cymerman et al., 2005; Gramatica et al., 2006; Mohammed and Markert, 2006). The process of urbanization and industrialization is accompanied by increased automobile and industrial emissions of heavy metals to surrounding water bodies (Arnason and Fletcher, 2003; Vaalgamaa, 2004). Except industrial emission, most heavy metals have significant traffic related sources (Callender and vanMetre, 1997; Gardner and Carey, 2004; Ona et al., 2006). Even treated urban effluents can serve as point sources of metal contaminants to receiving waters (Gobeil et al., 2005), and it has been shown that management of storm water in urban areas leads to the accumulation of polluted sediments at the water-sediment interface of various aquatic ecosystems (Mermillod-Blondin et al., 2005).

With population, economy, and industry rapidly growing in China, research is needed to understand the effects of development on the environment, before any preventive measures can be undertaken in the land-use systems and watersheds to reduce the pollution levels of heavy metals. In China, urban lakes often receive untreated sewage and polluted runoff. To assess the heavy metal distribution in urban lakes and its relationship with regional development, an urban lake in Wuhan City has been selected for study. For a long time, urban lakes have received storm runoff, 
urban sewage, and enriching urban landscapes in Wuhan City. A survey of the pollution status of urban lakes indicates that urban lakes in Wuhan City are heavily polluted by $\mathrm{N}$, P, and chemical oxygen demand (COD); and the decline of water quality has led to the decline of biodiversity (Wuhan Water Authority, 2005). Moshui Lake in Wuhan City is both a major sink for point and nonpoint pollution wastewaters and an important local fishery resource. This conflict of interests is common in China, making Moshui Lake a representative of urban lakes in China. Aquatic organisms can bioaccumulate, biomagnificate, or biotransfer certain metals to concentrations high enough to bring about harmful effects (Naimo, 1995), especially because of the transfer of metals through the food chain (Dallinger et al., 1987). The increasing frequencies of fish mortality in Moshui Lake and around China indicate the critical need for understanding and improving the quality of aquatic ecosystems. The determination of toxic pollutants in sediments is fundamental to the solution of many environmental problems (Weisz et al., 2000), and can be of great importance for local people's health (Graney and Eriksen, 2004). In this article, the authors have applied a four-step method to evaluate the extent, of distribution, and ecotoxicological effects of trace metal contamination in the Moshui Lake sediments.

\section{Materials and methods}

\subsection{Sampling locations}

Moshui Lake is located in Hanyang District, Wuhan City, China, with urban sewage and storm runoff contributing to most of the surface water. In the last 20 years, industry had developed rapidly in the Hanyang District. Meanwhile, the industry structure was continually adjusted, and environmental management was strengthened. As their synthetic effects, the maximum values of industry wastewater discharge and the concentrations of $\mathrm{Cr}, \mathrm{Cu}$, and $\mathrm{Ni}$ in the sediment appeared around 1994. Sampling sites across Moshui Lake (Fig.1) were chosen to assess spatial differences in trace metal concentrations of lake sediments. Site $\mathrm{B}$ and $\mathrm{D}$ represented the southern and northern riparian respectively. Site $\mathrm{C}$ was in the center of lake. Sites A and

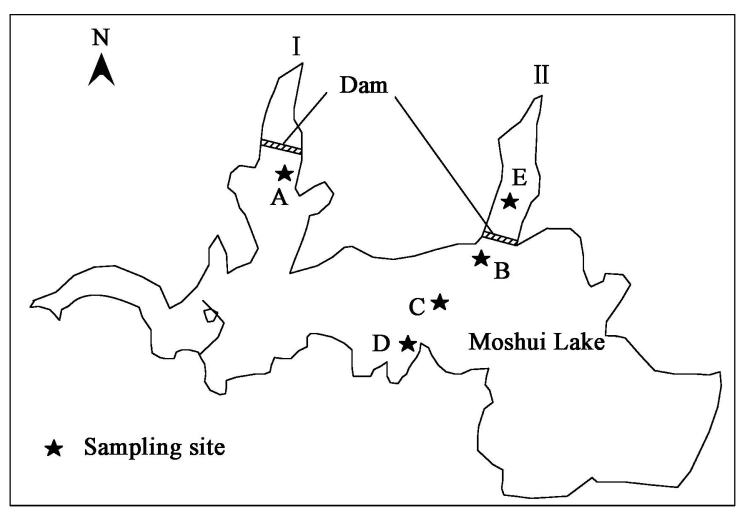

Fig. 1 Sampling sites in Moshui Lake.
E were sampled from two of the urban sewage and surface runoff outfalls (I and II in Fig.1 respectively).

\subsection{Physical and chemical parameters of the lake}

The climate is a typically subtropical monsoon climate with a mean annual temperature of $15.9^{\circ} \mathrm{C}$ and the mean annual precipitation of $1,350 \mathrm{~mm}$. This lake receives drainage from a basin of $18.00 \mathrm{~km}^{2}$ inhabited by 0.10 million people. Land use in the northern watershed boundary is dominated by urban uses (e.g., residential and commercial), whereas, land use near the southern boundary is predominately rural and agricultural. The average water depth of Moshui Lake is $1.2 \mathrm{~m}$, with a surface area of approximately $3.14 \mathrm{~km}^{2}$. There are 10 wastewater discharge points into the lake, and until 2000, the municipal effluents had entered the lake untreated. Urban sewage and storm runoff are also discharged into the lake at several outfalls. Annual inputs of COD, BOD, SS, TN, TP from these urban sewage and industry wastewater outfalls were $2409,614,1146,480$, and 24 t, respectively (Wuhan Water Authority, 2005). In addition to these point sources, nonpoint source pollution associated with stormwater runoff also substantially contributes to the poor water quality in Moshui Lake (Li et al., 2006).

\subsection{Sampling methods}

Sediment cores were collected using a gravity corer in September 2005. The core length was $60 \mathrm{~cm}$ and the diameter was $6 \mathrm{~cm}$. After the overlying water was siphoned off the sediment columns were sectioned into $2 \mathrm{~cm}$ slices. All the samples were sealed in clean polyethylene bags and put in a cooled box on site. The cooled samples were brought back to the lab to be air-dried until required.

\subsection{Sampling analysis}

Five commonly measured heavy metals $(\mathrm{Cr}, \mathrm{Cu}, \mathrm{Ni}$, $\mathrm{Pb}$, and $\mathrm{Zn}$ ) were detected in all the sediment samples. Each sample was duplicated, and the average was reported. Total metal analysis of the sediment was determined by digesting the sample with $\mathrm{HF}_{-} \mathrm{HClO}_{4}$ (Tessier et al., 1979). For the analysis of three metal forms, exchangeable and bound to carbonate, bound to $\mathrm{Fe} / \mathrm{Mn}$ oxide, and bound to organic matter and sulfide, a four-step method (Hlavay and Polyak, 1998) was used. The residual metal (Res) was measured according to the difference between the total metal concentration and the sum concentrations of the three forms. Leachate was analyzed using a PerkinElmer Elan 6000 ICP-OES for trace metal concentrations. Total organic matter (OM) was determined by ignition at $550^{\circ} \mathrm{C}$ for $2 \mathrm{~h}$ (Vollenweider, 1969).

\subsection{Pollution extent and risk assessment}

To assess metal concentrations in a sediment, two guidelines were applied in this study. One was the New York State Department of Environmental Conservation (NYSDEC, 1999) guideline. It proposed the lowest effect screening levels (LEL) for $\mathrm{Cr}, \mathrm{Cu}, \mathrm{Ni}, \mathrm{Pb}$, and $\mathrm{Zn}$, of $26,16,31,16$, and $120 \mathrm{mg} / \mathrm{kg}$, respectively, and severe effect screening levels (SEL) of 110, 110, 110, 50, and 
$270 \mathrm{mg} / \mathrm{kg}$, respectively. The pollution extent was assessed by two threshold values of LEL and SEL. If the LEL was exceeded, the metal could moderately impact biota health. If the SEL was exceeded, the metal could severely impact biota health (Graney and Eriksen, 2004). The other guideline was Risk Assessment Code (RAC) classification based on the percentage of metal in the carbonate and exchangeable fractions (Singh et al., 2005). As there were differences in toxic effects of the metals with different metals as well as their concentrations and the time of exposure (Mohammed and Markert, 2006), RAC assessed the availability of metals in sediments by applying a scale to the percentage of exchangeable and carbonate fractions. This was important because the fractions introduced by anthropogenic activities were typified by the adsorptive, exchangeable, and bound to carbonate fractions, which were weakly bonded metals that could equilibrate with the aqueous phase and thus became more rapidly bioavailable (Singh et al., 2005). According to the RAC guideline, for any metal, sediments with $11 \%-30 \%$ carbonate and exchangeable fractions would be at medium risk to the environment. Furthermore, the sedimentary metals with these fractions at more than $50 \%$ would be considered as a very high risk and could easily enter the food chain (Jain, 2004). Only the above surface $6 \mathrm{~cm}$ sediments were done with RAC, as the top part of the sediment was the most reactive with the overlying surface water (Sallade and Sims, 1997). Therefore, in this study, the mean concentration of the above three increments $(6 \mathrm{~cm})$ was used as the surface concentration for risk assessment.

\subsection{Historical development data collection}

To document the impact of industrialization and urbanization on the accumulation of heavy metals in sediments, the process of society and economy development in this district was studied. All the historical data about the GDP (gross domestic product), population, and wastewater discharge, both in Hanyang District and Wuhan City, was collected from the Wuhan Water Authority (2005) and the Wuhan Statistic Bureau (1984-2004).

\section{Results}

\subsection{Pollution extent assessment}

The $\mathrm{pH}$ value of the Moshui Lake sediment samples range from 5.1 to 8.0 , with the lowest value measured being in the surface sediment, at site $\mathrm{E}$. The organic matter concentration ranges from $4.2 \%$ to $23.7 \%$. The heavy metal concentrations in total and different forms are shown in Fig.2. From Fig.2, it can be seen that the trace metal concentrations at sites $\mathrm{B}$ and $\mathrm{D}$ are lower than those at the other sites, for total depth. High metal concentrations of sediment were observed at site $\mathrm{A}$, which indicated that the most severe pollution occurred at outfall I, where runoff and urban sewage were discharged. It was probably because of the abrupt reduction of the runoff velocity that most of the particles carrying metals in the runoff settled down.

\subsubsection{Chromium contamination}

At site $\mathrm{A}$, the maximum of total $\mathrm{Cr}$ concentrations appeared at the depth of $32 \mathrm{~cm}$ (Fig.2). Despite a decrease with the decrease of depth, above the depth of $30 \mathrm{~cm}$, the total $\mathrm{Cr}$ concentration in the surface sediment was still twice the SEL $(110 \mathrm{mg} / \mathrm{kg})$, and $\mathrm{Cr}$ concentration at the $32 \mathrm{~cm}$ depth was almost 16 times of the SEL. Although $\mathrm{Cr}$ concentration varied considerably less at the other sites across the total column depth, total $\mathrm{Cr}$ concentration at sites B, D, and E was above LEL (26 mg/ $\mathrm{kg}$ ) and below SEL. Total Cr concentration exceeded SEL at site C. The predominant speciation of $\mathrm{Cr}$ was different at different sites. At site $\mathrm{A}$, most of the $\mathrm{Cr}$ was bound to the organic matter $(>60 \%)$. At sites B, D, and E, the residual form was dominant $(>60 \%)$. For all these sites, the least $\mathrm{Cr}$ pool was exchangeable and bound to the carbonate fraction.

\subsubsection{Copper contamination}

The distribution of $\mathrm{Cu}$ in total and different forms was similar to that of $\mathrm{Cr}$ (Fig.2), with the same concentration order: sites $\mathrm{D}<\mathrm{B}<\mathrm{C}<\mathrm{E}<\mathrm{A}$. Total $\mathrm{Cu}$ concentration at the surface sediment of site A was almost twice as much as SEL $(110 \mathrm{mg} / \mathrm{kg})$, and more than 11 times of the SEL at the depth of $32 \mathrm{~cm}$. Total Cu concentration was above LEL (16 $\mathrm{mg} / \mathrm{kg}$ ) and below SEL at sites B and D. At all sites except A, the combination of both organic matters bound and residual $\mathrm{Cu}$ forms dominated in all the sediment cores. At site $\mathrm{A}$, the exchangeable and bound to carbonate $\mathrm{Cu}$ form played a more important role in the total $\mathrm{Cu}$ concentrations than at the other sites (Fig.2).

\subsubsection{Nickel contamination}

Total Ni concentration exhibited near or above SEL $(50 \mathrm{mg} / \mathrm{kg})$ at all sites. The maximum $\mathrm{Ni}$ concentration appeared at the depth of $30 \mathrm{~cm}$ at site A, which was four times the SEL. A relatively constant Ni concentration was detected across the sediment column for the other sites (northern and southern riparian, lake center, and outfall II), and the values were above/below the SEL and LEL. The predominant speciation of $\mathrm{Ni}$ was the residual form accounting for about $60 \%$ of total $\mathrm{Ni}$ at all sites, and the remaining $40 \%$ was equally divided into the other three forms (Fig.2). Exchangeable and bound to carbonate $\mathrm{Ni}$ form dominated the total $\mathrm{Ni}$ concentrations at the depth of about $30 \mathrm{~cm}$ at site $\mathrm{A}$, and the fraction of residual $\mathrm{Ni}$ form dominated in all the other sediment cores.

\subsubsection{Lead contamination}

At sites $\mathrm{B}$ and $\mathrm{D}$, total $\mathrm{Pb}$ concentration was above LEL (31 mg/kg), but far below SEL (110 mg/kg). Total $\mathrm{Pb}$ concentration at site $\mathrm{C}$ was near to SEL, and at sites $\mathrm{A}$ and $\mathrm{E}$ above it. Relatively constant concentrations of total $\mathrm{Pb}$ were observed across the sampled depths at site $\mathrm{B}$, whereas, at sites $\mathrm{D}$ and $\mathrm{E}$ the total $\mathrm{Pb}$ concentrations seemed to increase with the decrease in depth. At sites A and $\mathrm{C}$, total $\mathrm{Pb}$ concentrations first increased with decrease in depth (below 24 and $16 \mathrm{~cm}$, respectively) and then kept a constant value in the shallow sediments (Fig.2). Exchangeable and carbonate bound $\mathrm{Pb}$ contributed less 

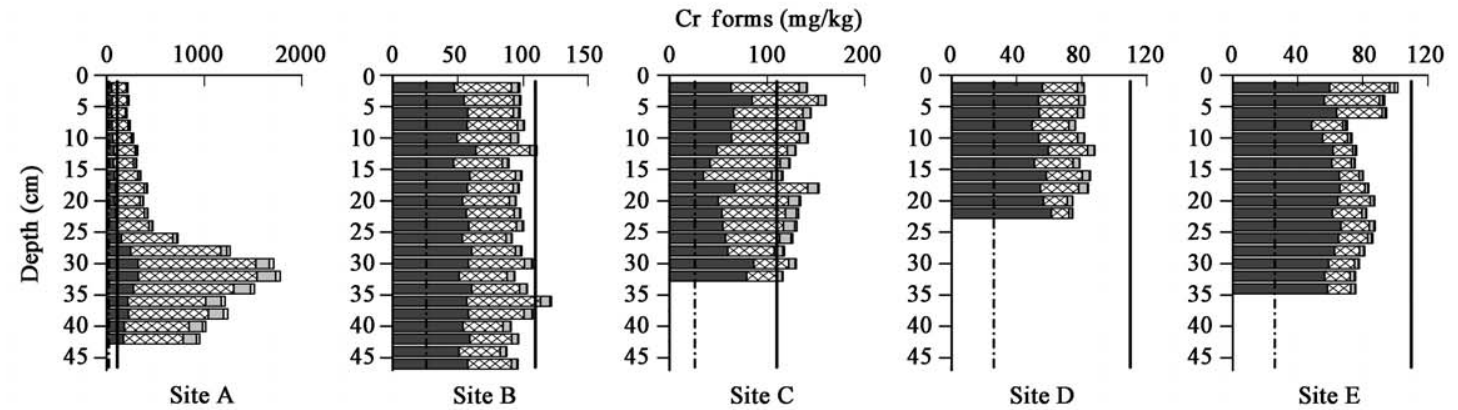

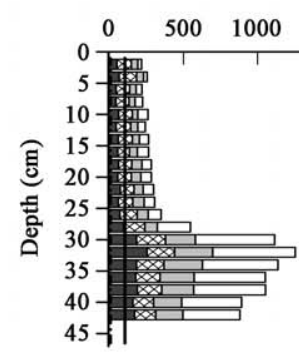

Site A

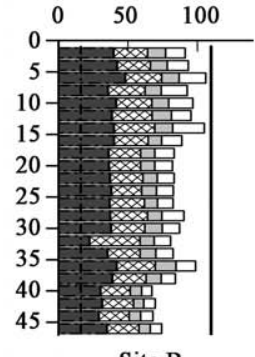

Site B
$\mathrm{Cu}$ forms $(\mathrm{mg} / \mathrm{kg})$

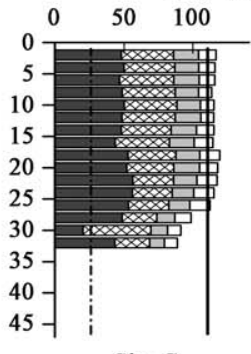

Site C

Ni forms (mg/kg)

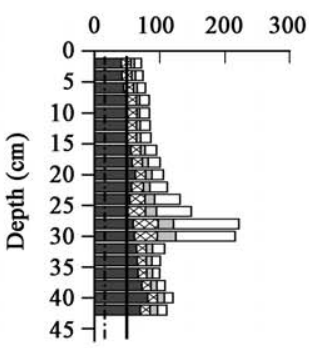

Site A
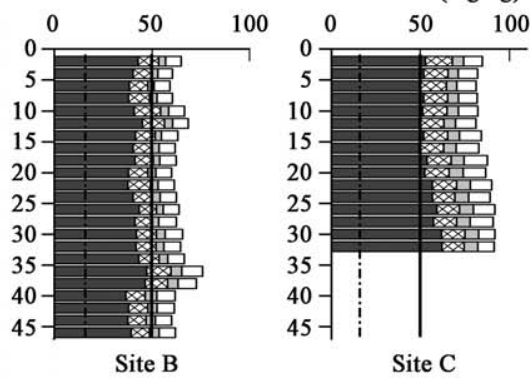

Site C

$\mathrm{Pb}$ forms $(\mathrm{mg} / \mathrm{kg})$
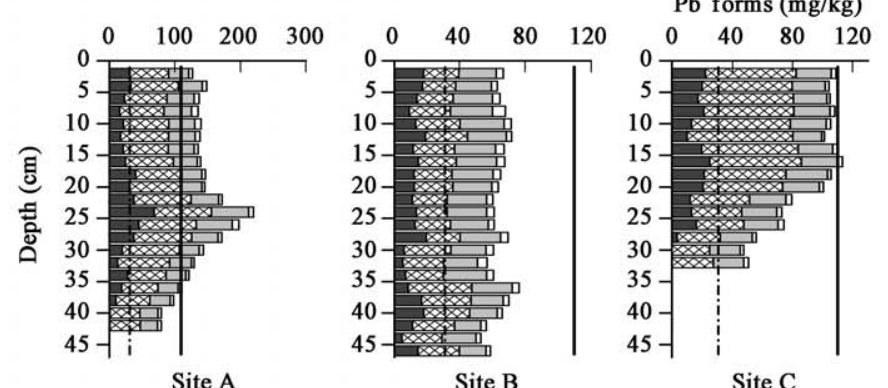

Site C

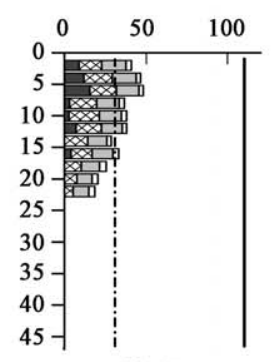

Site D

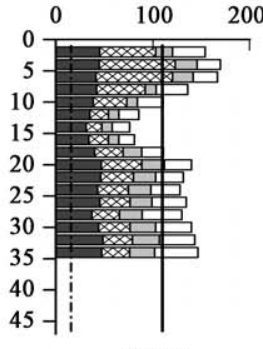

Site E

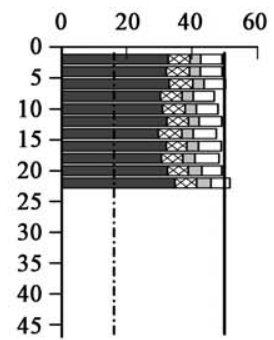

Site D

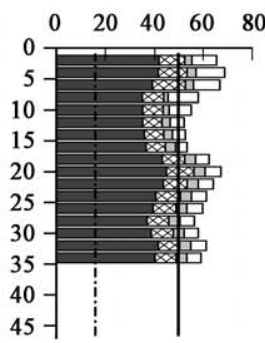

Site E

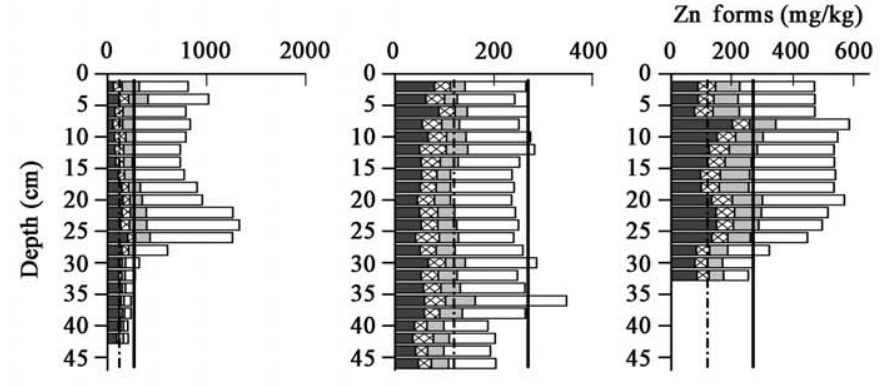

Site A

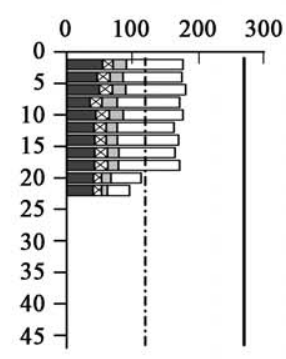

Site D

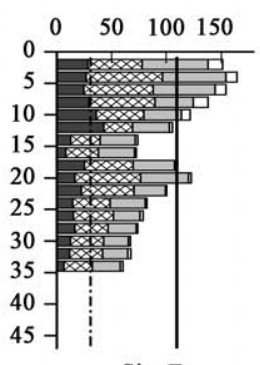

Site E

Fig. 2 Metal concentrations in fractions of sediment cores. The NYSDEC lowest effect level (LEL) and severe effect level (SEL) are shown as the dash line and solid line, respectively. 
than $6.5 \%$ of the $\mathrm{Pb}$ forms, and the other three forms dominatated $\mathrm{Pb}$ forms at all the sites.

\subsubsection{Zinc contamination}

The distribution of the total and different forms of $\mathrm{Zn}$ was similiar to that of $\mathrm{Pb}$ (Fig.2). Total $\mathrm{Zn}$ concentrations at the surface sediment of sites $A$ and $C$ were near to or more than twice of the SEL $(270 \mathrm{mg} / \mathrm{kg})$. At site $\mathrm{D}$, the total $\mathrm{Zn}$ concentration was above LEL (120 mg/kg), but below SEL. At sites B and E, they were near to or above SEL. Unlike the other detected metals, the predominant speciation of $\mathrm{Zn}$ was exchangeable and bound to carbonate form $(46 \%-62 \%)$. The biggest fractions $(29.8 \%$ and $28.42 \%$ ) of residual $\mathrm{Zn}$ form were found at sites B and D, with the least fraction of residual $\mathrm{Zn}$ form $(9.56 \%)$ at site A (Fig.2).

\subsection{Risk assessment code (RAC)}

The percentages of metals in the exchangeable and carbonate-bound forms for the sediment samples above $6 \mathrm{~cm}$ (Fig.3) indicated that all the study sites exhibited almost the same percentage values for a certain metal. The fractions of $\mathrm{Cr}$ and $\mathrm{Pb}$ below $10 \%$ posed a low risk to the environment. With fractions of $\mathrm{Zn}$ at nearly $50 \%$, the RAC was classified as very high. The authors' findings of $11 \%-$ $20 \%$ carbonate and exchangeable $\mathrm{Cu}$ and $\mathrm{Ni}$ fractions placed all these sites in the medium risk category.

\subsection{Process of industrialization and urbanization in Hanyang District}

Investigation data showed that the process of industria-

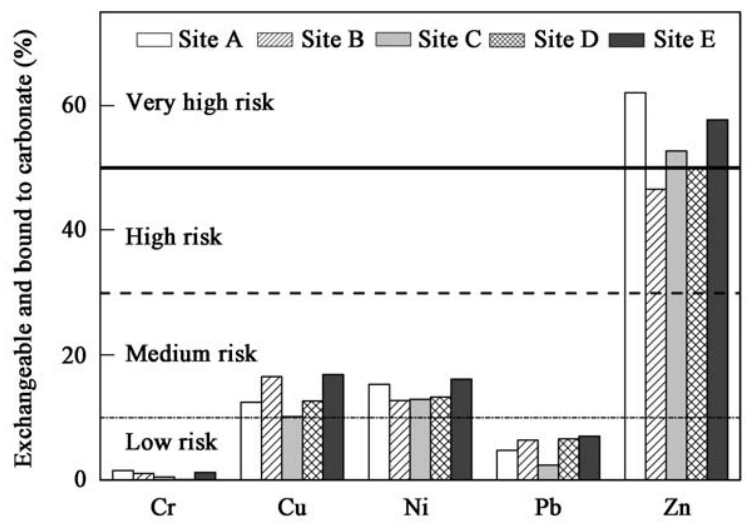

Fig. 3 Percentage of exchangeable and bound to carbonate of the surface sediments.

Table 1 Changes of industrial waste water emission and urban sewage discharge in Hanyang District of Wuhan City, 1986-2003*

\begin{tabular}{llllll}
\hline Year & \multicolumn{2}{l}{ Industrial wastewater emission } & & \multicolumn{2}{l}{ Urban sewage discharge } \\
\cline { 2 - 3 } \cline { 5 - 6 } & $\begin{array}{l}\text { Volume } \\
\left(\times 10^{4} \mathrm{~m}^{3}\right)\end{array}$ & $\begin{array}{c}\text { Ratio } \\
\text { treated }(\%)\end{array}$ & & $\begin{array}{l}\text { Volume } \\
\left(\times 10^{4} \mathrm{~m}^{3}\right)\end{array}$ & $\begin{array}{c}\text { Ratio } \\
\text { treated }(\%)\end{array}$ \\
\hline 1986 & 2236.4 & 55.7 & 2017.3 & No \\
1988 & 2086.8 & 71.3 & 2054.5 & No \\
1991 & 1997.5 & 70.4 & 2138.8 & No \\
1994 & 2023.3 & 59.6 & 2583.7 & No \\
1997 & 1608.0 & 64.5 & 1934.7 & No \\
2001 & 1352.4 & 98.3 & 1815.8 & No \\
2003 & 1258.7 & 98.5 & 1906.0 & No \\
\hline
\end{tabular}

No: not treated. * Wuhan Statistic Bureau, 1984-2004.

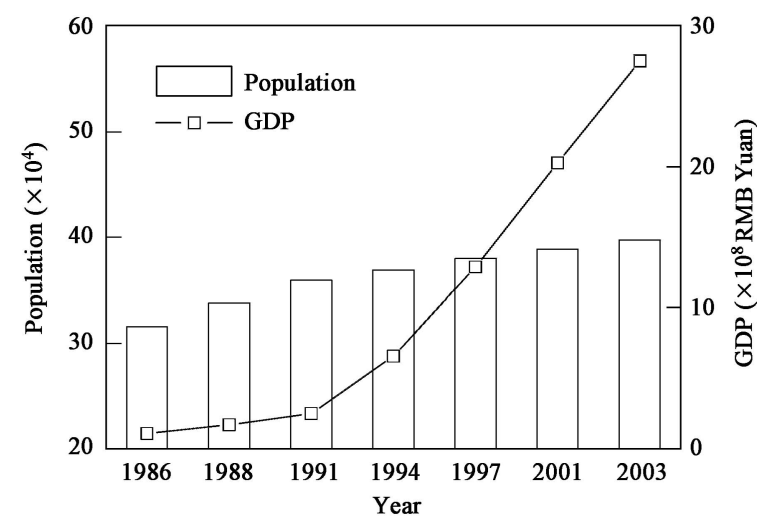

Fig. 4 Changes of population and GDP in Hanyang District of Wuhan City, 1986-2003 (Wuhan Statistic Bureau, 1984-2004).

lization and urbanization correlated well with the accumulation of heavy metals in the sediments of Moshui Lake. Since 1979, urbanization and economy have kept developing rapidly in Hanyang District, Wuhan City. The changes of population and GDP from 1986 to 2003 in this district are shown in Fig.4. Table 1 presents the changes of industrial wastewater and sewage discharge during this period. Both the industrial wastewater and sewage discharge volumes reached the maximum in 1994, after which the volume of discharge declined, whereas, economy still developed. This decline of wastewater discharge and increase of the treatment ratio in recent years could be attributed to the synthetic effect of the change in industry structure and strengthening of environmental management.

The effect of point source coming from industrialization process on the sedimentary metals is illustrated by the sediment column at site A in outfall I (Fig.2). Among the industry works located in the watershed, the electroplating plants imposed the greatest impact on the heavy metal pollution of the aquatic system. A bicycle rim plant, where the electroplating process of $\mathrm{Cr}, \mathrm{Cu}$, and $\mathrm{Ni}$ was conducted, existed from 1970s to 1994. In 1995, this plant collapsed and another hardware plant was set up at the same site. The new plant used a new process to electroplate $\mathrm{Zn}$. At site A, $\mathrm{Zn}$ concentration in the sediment increased dramatically with the decrease of depth, above the depth of $30 \mathrm{~cm}$ (Fig.2), which corresponded with the year 1995, when Zn electroplating began to boom. The decreased tendency of $\mathrm{Cr}, \mathrm{Cu}$, and $\mathrm{Ni}$ with decreasing depth for the same above $30 \mathrm{~cm}$ surface sediments at site A confirmed this sediment dating.

Without industry factories in the watershed, outfall II only received sewage and polluted runoff, which indicated that the effect of diffuse source and sewage source, coming from the urbanization process, on the sedimentary metals, could be elucidated by the sediment column at site E. With the rapid process of urbanization, the GDP increased, the population expanded, and the number of automobiles increased dramatically. At site $\mathrm{E}$, the concentrations of sedimentary $\mathrm{Cr}, \mathrm{Cu}$, and $\mathrm{Ni}$ kept nearly constant, whereas, the concentrations of sedimentary $\mathrm{Pb}$ and $\mathrm{Zn}$ showed a tendency to increase with decreasing depth for the sampled depth (Fig.2). In summary, the metal distribution curves 
at site $\mathrm{E}$ indicated that urbanization resulted in rising concentrations of $\mathrm{Pb}$ and $\mathrm{Zn}$ in urban lake sediments.

\section{Discussion}

In this study, nearly $20 \%$ of the total $\mathrm{Pb}$ concentrations existed in residual $\mathrm{Pb}$ forms, in agreement with others' findings (Gobeil et al., 2005) on the importance of bound organic and sulfide $\mathrm{Pb}$ (Weisz et al., 2000), with $\mathrm{Pb}$ forming the stable organic complexs and binding to the sulfide. At all these sites, the exchangeable and carbonate bound $\mathrm{Zn}$ accounted for $50 \%-60 \%$ of the total $\mathrm{Zn}$ concentration, similar to the results of other water bodies (Weisz et al., 2000). The relatively high percentages of exchangeable and carbonate bound $\mathrm{Cu}, \mathrm{Ni}$, and $\mathrm{Zn}$ (Fig.3) indicated that these metals from wastewater existed as adsorbed phases on the surface of sediments (Kim et al., 1998).

Concentrations of the five metals $(\mathrm{Cr}, \mathrm{Cu}, \mathrm{Ni}, \mathrm{Pb}, \mathrm{Zn})$ in sediments of this urban lake were higher or comparable to the findings from other lakes, reservoirs, or retention ponds draining urban areas (Table 2). For the reason that the sediments reflect the history of the water body pollution (Jain, 2004), the sediments in Moshui Lake could well offer an effective archive of the industrialization and urbanization process in Wuhan City, even without sediment dating.

Because of the limitation of the core length, the metal background value in the sediment could not be assessed from the sampled sediment. To evaluate the metal background value, three replicate surface soil samples were obtained from the nearby hillslope. And the metal background levels were determined as 58.8, 37.8, 39.1, 10.7, and $59.9 \mathrm{mg} / \mathrm{kg}$ for $\mathrm{Cr}, \mathrm{Cu}, \mathrm{Ni}, \mathrm{Pb}$, and $\mathrm{Zn}$, respectively. Compared with these background levels, it could be seen that high amounts of metals had accumulated in the lake sediments. In this study, different risk levels were obtained from the two methods adopted, to evaluate the heavy metal pollution. For example, although in the surface sediments at most sites the total contents of $\mathrm{Cr}$ were near to or above SEL, the value of low risk was still obtained from the RAC. However, these differences were reasonable because of the difference in the existing chemical forms among different metals.

In Wuhan City including the Hanyang District, the traditional industry of metallurgy and machine manufactures have been closed or moved to suburban areas. This industry has been replaced by technology development sectors, such as, mobile, microelectronic, and bioengineering, in the urban areas, resulting in changes in sources and types of industrial wastewater. This decline of wastewater discharge in the recent 10 years (Table 1) could be partly attributed to the effect of this change in industry. In this study, the traditional electroplating process was found to have led to high accumulation of $\mathrm{Cr}, \mathrm{Cu}$, and $\mathrm{Ni}$ in urban lake sediments. Also the boom in the $\mathrm{Zn}$ electroplating process resulted in high concentration of $\mathrm{Zn}$ in sediments of the receiving water body, despite the decline in concentrations of $\mathrm{Cr}, \mathrm{Cu}$, and $\mathrm{Ni}$.

Except for industrial emission, these five metals have significant traffic related sources (Callender and vanMetre, 1997; Gardner and Carey, 2004). With the rapid process of urbanization, the number of automobiles and the impervious surface ratio increased dramatically, which would indefinitely result in these heavy metals depositing in the lake sediments of the receiving water bodies.

When compared with the economic growth, the development of wastewater treatment facilities was disappointing. Until 2002, there were only five wastewater treatment facilities in Wuhan City, and four of them were in operation with a cumulative capacity of only $21 \%$ (Wuhan Water Authority, 2005), with none of the facilities located in the Hanyang District. The importance of wastewater treatment is demonstrated at site $\mathrm{E}$, which received untreated urban sewage and storm runoff and where metals concentrations appeared to be increasing or remaining constant.

By relating the industrialization and urbanization process to the vertical distribution curves at these sites, it is believed that the high trace metal concentrations of sediment in Moshui Lake result from rapid urbanization and industrialization, and lack of wastewater treatment.

Fortunately, the worsening trend of water quality has been addressed by a government effort to strengthen environmental management. With the progress of industrial pollution control, industrial wastewater emission volume decreased and the ratio treated increased (Wuhan statistic Bureau, 1984-2004). Meanwhile, the sewage treatment and water saving strategy were being developed in this area. The stormwater runoff pollution was also being paid more attention. In 2006, the outfall I studied in this study was closed, and the sewage and polluted runoff were converted to the new built urban sewage treatment plant. With all these strategies being conducted, the following metal accumulation profile should show some new characteristics, different from the past.

Because aquatic organisms are exposed to metals that

Table 2 Maximum $\mathrm{Cr}, \mathrm{Cu}, \mathrm{Ni}, \mathrm{Pb}$, and $\mathrm{Zn}$ concentrations in sediments in Moshui Lake and other selected water bodies from literature *

\begin{tabular}{|c|c|c|c|c|c|c|}
\hline \multirow[t]{2}{*}{ Site } & \multirow[b]{2}{*}{$\mathrm{Cr}$} & \multicolumn{4}{|c|}{ Maximum concentration (mg/kg) } & \multirow[t]{2}{*}{ Reference } \\
\hline & & $\mathrm{Cu}$ & $\mathrm{Ni}$ & $\mathrm{Pb}$ & $\mathrm{Zn}$ & \\
\hline Moshui Lake, China & 1,779 & 1,249 & 222 & 220 & 1,337 & This study \\
\hline Zrich Lake, Switzerland & - & 77 & - & 150 & 675 & Von Gunten et al., 1997 \\
\hline J. A. Alzate Reservoir, Mexican & 145 & 61 & 43 & 76 & 233 & Avila-Pérez et al., 1999 \\
\hline Ataturk Dam Lake, Turkey & - & 23 & 140 & - & 61 & Karadede and Ünlü, 2000 \\
\hline Patroon Reservoir, USA & - & - & - & 3,600 & - & Arnason and Fletcher, 2003 \\
\hline Kolleru Lake, India & 78 & 610 & 2 & 6 & 714 & Chandra Sekhar et al., 2003 \\
\hline Storm water retention pond, New York, USA & 8 & 46 & 13 & 110 & 300 & Graney and Eriksen, 2004 \\
\hline Gomti River, India & 19 & 35 & 30 & 75 & 101 & Singh et al., 2005 \\
\hline
\end{tabular}

* All results are given in terms of the dry weight of material analyzed. 
are dissolved in water, associated with suspended particles, and deposited in bottom sediments, they can bioaccumulate, biomagnificate, or biotransfer certain metals to concentrations high enough to bring about harmful effects (Naimo, 1995). This is particularly problematic as metals transfer through food chain (Dallinger et al., 1987). The vertical distributions of metals in undisturbed sediments reflect past exposure to the water column and constitute a quantitative record of water quality (Gerritse et al., 1998). Therefore, at the depth of $30-32 \mathrm{~cm}$ at site A, this urban lake would expose the most serious risk to aquatic biota health, cascading up to result in effects on the local people for the highest sedimentary metal concentrations. Although the adjustment of industry structure and construction of wastewater plants have led to the reduction of heavy metal accumulation in lake sediments of late, there are still high metal concentrations in the surface sediments and the resulting high risk assessment values indicate that the urban lake should receive high priority for wastewater treatment. Remediation techniques are particularly critical for the untreated wastewater outfalls as well as the areas of urban lakes that are already contaminated. Remediation techniques may include physical treatment, such as, dredging, capping, and bioremediation, which can control contaminated sediments relatively easily (Chen and Chen, 2002). However, the maximum values at various depths in Moshui Lake indicate that the dredging depth must be considered carefully to avoid re-releasing toxic metals into the water above, if dredging sludge is considered. The heavy metal distribution profile should be studied first to make sure that all of the most polluted sediments can be dredged out.

\section{Conclusions}

In conclusion, because of the lack of wastewater treatment, rapid urbanization and industrialization have resulted in accumulation of heavy metals in sediments of urban lakes in China. The extreme values of $\mathrm{Cr}$ and $\mathrm{Cu}$ can even be 10 times more than the SEL values in the sediment cores at the outfall, where runoff and urban sewage are discharged. A very high and medium risk can be assessed for the sedimentary $\mathrm{Zn}$, and the group of $\mathrm{Cu}$ and $\mathrm{Ni}$, respectively. The result of the risk assessment code indicates that the metal bioavailability is a significant cause of decline in urban lakes across China, and that enhanced strategies should target the capture and removal of metals. However, the dredging depth must be considered carefully to avoid re-releasing toxic metals into the water column if dredging sludge is considered.

\section{Acknowledgements}

This work was supported by the Hi-Tech Research and Development Program (863) of China (No. 2002AA601022), the Chinese Academy of Sciences for Key and Innovation Project (No. KZCX1-SW-12) and the Innovation Program of Chinese Ministry of Water Resource (No. SCX2003-02-04). Special thanks to Ms. Desiree Tullos for her kind help in language correction.
The authors also wish to thank Mr Xuehong Kong for his assistance in the sampling.

\section{References}

Allen H E, Hansen D J, 1996. The importance of trace metal speciation to water quality criteria. Water Environment Research, 68: 42-54.

Arnason J G, Fletcher B A, 2003. A 40+ year record of Cd, Hg, $\mathrm{Pb}$, and $\mathrm{U}$ deposition in sediments of Patroon Reservoir, Albany County, NY, USA. Environmental Pollution, 123: 383-391.

Avila-Pérez P, Balcázar M, Zarazúa-Ortega G, Barceló-Quintal I, Díaz-Delgado C, 1999. Heavy metal concentrations in water and bottom sediments of a Mexican reservoir. The Science of the Total Environment, 234: 185-196.

Billon G, Ouddane B, Recourt P, Boughriet A, 2002. Depth variability and some geochemical characteristics of $\mathrm{Fe}, \mathrm{Mn}$, $\mathrm{Ca}, \mathrm{Mg}, \mathrm{Sr}, \mathrm{S}, \mathrm{P}, \mathrm{Cd}$ and $\mathrm{Zn}$ in anoxic sediments from Authie Bay (Northern France). Estuarine Coastal and Shelf Science, 55: 167-181.

Callender E, van Metre P C, 1997. Reservoir sediment cores show US lead declines. Environmental Science and Technology, 31: A424-A428.

Chandra Sekhar K, Chary N S, Kamala C T, Suman Raj D S, Sreenivasa Rao A, 2003. Fraction studies and bioaccumulation of sediment-bound heavy metals in Kolleru lake by edible fish. Environment International, 29: 1001-1008.

Charkhabi A H, Sakizadeh M, Rafiee G, 2005. Seasonal fluctuation in heavy metal pollution in Iran's Siahroud River. Environmental Science and Pollution Research, 12: 264270.

Chen H L, Chen Y X, 2002. Progress of remediation techniques for polluted sediment. Agro-environmental Protection, 21: 179-182.

Dallinger R, Prosi F, Segner H, Back H, 1987. Contaminated food and uptake of heavy metals by fish: a review and a proposal for further research. Oecologia, 73: 91-98.

Fan C X, Zhu Y X, Ji Z J, Zhang L, Yang L Y, 2002. Characteristics of the pollution of heavy metals in the sediments of Yilihe River, Taihu Basin. Journal of Lake Sciences, 14(3): 235-241.

Gardner C B, Carey A E, 2004. Trace metal and major ion inputs into the Olentangy River from an urban storm sewer. Environmental Science and Technology, 38: 5319-5326.

Gerritse R G, Wallbrink P J, Murray A S, 1998. Accumulation of phosphorus and heavy metals in the Swan-Canning Estuary, Western Australia. Estuarine Coastal and Shelf Science, 47: $165-179$.

Gobeil C, Rondeau B, Beaudin L, 2005. Contribution of municipal effluents to metal fluxes in the St. Lawrence River. Environmental Science and Technology, 39: 456-464.

Gramatica P, Battaini F, Giani E, Papa E, Jones R J A, Preatoni D, Cenci R M, 2006. Analysis of mosses and soils for quantifying heavy metal concentrations in Sicily: A multivariate and spatial analytical approach. Environmental Science and Pollution Research, 13: 28-36.

Graney J R, Eriksen T M, 2004. Metals in pond sediments as archives of anthropogenic activities: a study in response to health concerns. Applied Geochemistry, 19: 1177-1188.

Han Y M, Du P X, Cao J J, Posmentier, E S, 2006. Multivariate analysis of heavy metal contamination in urban dusts of Xi'an, Central China. Science of the Total Environment, 355: 176-186. 
Hlavay J, Polyak K, 1998. Chemical speciation of elements in sediment samples collected at Lake Balaton. Microchemical Journal, 58: 281-290.

Jain C K, 2004. Metal fractionation study on bed sediments of River Yamuna, India. Water Research, 38: 569-578.

Karadede H, Ünlü E, 2000. Concentration of some heavy metals in water, sediment and fish species from the Ataturk Dam Lake (Euphrates), Turkey. Chemosphere, 41: 1371-1376.

Kim K W, Myung J H, Ahn J S, Chon H T, 1998. Heavy metal contamination in dusts and stream sediments in the Taejon area, Korea. Journal of Geochemical Exploration, 64: 409419.

Lee S, Moon J W, Moon H S, 2003. Heavy metals in the bed and suspended sediments of Anyang River, Korea: Implications for water quality. Environmental Geochemistry and Health, 25: 433-452.

Li L Q, Yin C Q, He Q C, Kong L L, Liu H L, 2006. Catchmentscale pollution process and first flush of urban storm runoff in Hanyang, Wuhan City. Acta Scientiae Circumstantiae, 26: 1057-1061.

McAlister J J, Smith B J, Neto J B, Simpson J K, 2005. Geochemical distribution and bioavailability of heavy metals and oxalate in street sediments from Rio de Janeiro, Brazil: A preliminary investigation. Environmental Geochemistry and Health, 27: 429-441.

Mermillod-Blondin F, Nogaro G, Datry T, Malard F, Gibert J, 2005. Do tubificid worms influence the fate of organic matter and pollutants in stormwater sediments? Environmental Pollution, 134: 57-69.

Mohammed M H, Markert B, 2006. Toxicity of heavy metals on Scenedesmus quadricauda (Turp.) de Brebisson in batch cultures. Environmental Science and Pollution Research, 13: $98-104$

Naimo T J, 1995. A review of the effects of heavy-metals on fresh-water mussels. Ecotoxicology, 4: 341-362.

NYSDEC (NewYork State Department of Environmental Conservation), 1999. Technical Guidance for Screening Contaminated Sediments. Department of Fish, Wildlife and Marine Resources, Albany, New York.
Ona L F, Melinda A, Alberto P, Prudente J A, Sigua G C, 2006. Levels of lead in urban soils from selected cities in a central region of the Philippines. Environmental Science and Pollution Research, 13: 177-183.

Sallade Y E, Sims J T, 1997. Phosphorus transformations in the sediments of Delaware's agricultural drainageways: I. Phosphorus forms and sorption. Journal of Environmental Quality, 26: 1571-1579.

Samecka-Cymerman A, Kolon K, Kempers A J, Jansen J, Boonen B, 2005. Bioaccumulation of elements in bryophytes from Serra da Estrela, Portugal, and Veluwezoom, the Netherlands. Environmental Science and Pollution Research, 12: 71-79.

Singh K P, Mohan D, Singh V K, Malik A, 2005. Studies on distribution and fractionation of heavy metals in Gomti river sediments-a tributary of the Ganges, India. Journal of Hydrology, 312: 14-27.

Tessier A, Campbell P G C, Bisson M, 1979. Sequential extraction procedure for the speciation of particulate trace metals. Analytical Chemistry, 51: 844-851.

Vaalgamaa S, 2004. The effect of urbanisation on Laajalahti Bay, Helsinki City, as reflected by sediment geochemistry. Marine Pollution Bulletin, 48: 650-662.

Vollenweider R A (ed.), 1969, A manual on methods for measuring primary production in aquatic environments. Oxford: Blackwell Scientific Publishers.

Von Gunten H R, Sturm M, Moser R N, 1997. 200-year record of metals in lake sediments and natural background concentrations. Envrionmental Science and Technology, 31: 2193-2197.

Weisz M, Polyak K, Hlavay J, 2000. Fractionation of elements in sediment samples collected in rivers and harbors at Lake Balaton and its catchment area. Microchemical Journal, 67: 207-217.

Wuhan Statistic Bureau, 1984-2004. Wuhan annual statistics. Wuhan Municipal Government: Chinese Statistics Press.

Wuhan Water Authority, 2005. Management and protection project of water environment in Wuhan. Wuhan Municipal Government: Chinese Statistics Press. 